\title{
Preparing a Profession: Development and Design of a Merged Program
}

\author{
Denise A. Soares, Ann Monroe, Susan S. McClelland \\ Department of Teacher Education, University of Mississippi, MS, USA \\ Email: dasoares@olemiss.edu
}

How to cite this paper: Soares, D. A., Monroe, A., \& McClelland, S. S. (2017). Preparing a Profession: Development and Design of a Merged Program. Creative Education, $8,1329-1338$.

https://doi.org/10.4236/ce.2017.88094

Received: June 17, 2017

Accepted: July 22, 2017

Published: July 25, 2017

Copyright $\odot 2017$ by authors and Scientific Research Publishing Inc. This work is licensed under the Creative Commons Attribution International License (CC BY 4.0).

http://creativecommons.org/licenses/by/4.0/

\begin{abstract}
The need for improved teacher training arises from the limitations of current teacher training programs. In many universities, general and special education programs continue to operate under separate models. Research shows teacher preparation programs failed to prepare general educators for the challenges of inclusion and collaborative teaching environments. The purpose of this report is to discuss the impetus for the program redesign by describing the outcomes of the joint venture between faculty in the Elementary, Secondary, and Special Education programs. A thorough description of the program (e.g. admissions, course sequence, action labs, and field experiences) as well as critical components will be discussed.
\end{abstract}

\section{Keywords}

Elementary Education, Special Education, Merged Program, Teacher Training, Teacher Preparation

\section{Introduction}

Federal legislation (No Child Left Behind [NCLB], 2001, Individuals with Disabilities Education Improvement Act [IDEIA], 2014) forced public schools to increase the performance of all students by focusing on standards-based instruction and accountability. Most recently, Every Student Succeeds Act (ESSA, 2016) continues this mission. Classrooms are becoming more inclusive by meeting the diverse needs of all students. These inclusive classrooms have changed our thinking about the knowledge and skills that both general and special educators need to be successful in today's classrooms. More apparent is the need to prepare multitalented, collaborative educators to meet the educational needs of the diverse children in our public-school classrooms.

In many university teacher preparation programs, a discussion has begun be- 
tween special and general education program faculty on how to prepare educators to be successful with a diverse population of students. As legislation continues to focus on positive outcomes for all learners in the general education setting (President's Commission on Excellence in Special Education 2002; Brownell et al., 2010), preparation programs need to focus their efforts on preparing teachers who are able to work collaboratively with other teachers upon entering the profession (Brownell et al., 2010; Kamens, 2007; Shippen, Crites, Houchins, Ramsey, \& Simon, 2005; Van Laarhoven, Munk, Lynch, Bosma, \& Rouse, 2007).

The purpose of this paper is to discuss the impetus for the program redesign by describing the outcomes of the joint venture between faculty in the Elementary, Secondary, and Special Education programs. A thorough description of the program (e.g. admissions, course sequence, action labs, and field experiences) and its critical components are discussed.

\section{Impetus, Purpose, and Goals}

Teacher preparation programs must prepare effective professional educators who advocate for diverse learners through strong content knowledge, pedagogical skills in both special and general education, and intervention skills in the use of evidence-based practices. The goal of our 2010 program redesign was to create an integrated elementary special education preservice licensure program. In doing so, we sought to adapt Blanton and Pugach's (2007) model of a merged elementary/special education program through offering content in a single curriculum that is completely integrated, including all courses and field experiences (Blanton \& Pugach, 2007: p. 23). Restructuring allowed us to abandon our single elementary licensure program in order to build a cohesive integrated program.

Our plan was to effect change in the teacher education program by setting new, more inclusive goals and transforming the way instruction was delivered to our preservice teachers. Two crucial components of the plan were to modify the role of faculty and provide our students with a more authentic preparation experience through action labs and field experiences that placed our students directly in diverse elementary and special education classrooms. We applied the theoretical foundation provided by Cuban (1992) to K-12 schools to the University setting. We attempted to construct the program so that faculty could first overcome initial resistance that accompanies first-order change (i.e. changes to an organization), but have a structure in place that encouraged second-order change (i.e. goals and potential roles of faculty) as faculty developed new courses through developing new content.

Our undergraduate programs offer learning experiences that promote the acquisition of knowledge, skills, and dispositions to facilitate lifelong learning in an interactive and diverse society. These experiences center around the five components of the conceptual framework, which provides a foundation for preparing candidates who can positively impact students to be productive and caring citizens: 1) effective communicators, 2) problem solvers, 3) lifelong learners, 4) users of technology, and 5) advocates for diverse learners. 
Conscious efforts were made to use vertical and horizontal alignment to ensure accreditation standards, Interstate Teacher and Assessment and Support Consortium (InTASC), Council for Exceptional Children initial standards, and testing standards (PRAXIS) for preservice teachers were integrated throughout the curriculum. We focused on blending of knowledge learned in coursework and further developed in communities of practice with teaching skills developed in field experiences, action labs, and practicums.

\section{New Program Coursework}

The overall purpose of the merged program was to develop strategic teachers with the versatility to meet the learning needs of all elementary students. Once a shared vision and goals were developed, the faculty engaged in a curricular mapping process to examine and then merge the programs in a way that would achieve these goals and meet licensure requirements in special and elementary education. The various standards and competencies (e.g., INTASC, CEC, Mississippi teacher standards), the content and skills, the key assignments and performance measures in each of the separate programs we remapped out and fully described. Then, the team identified where these elements were redundant or unique whereby reducing the General Education Courses and increasing the Professional Education Courses. This process resulted in a working draft of the scope and sequence of the new program's courses and field experiences. In Mississippi, the special educator licensure is categorical. The final program resulted in the inclusion of the 12 hours needed for a Special Education Mild/Moderate Endorsement according to Licensure guidelines. Those 4 courses include: 1) Introduction to Special Education; 2) Classroom \& Behavior Management; 3) Instructional Strategies for the Diverse Learner; and 4) Special Education Law and are found in the Professional Education Category.

The B.A.E. in Elementary Education with Special Education endorsement is a minimum 124 semester hours program that includes two concentration areas selected by the candidate in the areas of English, math, science, social studies, fine arts, foreign language and/or computers. The degree program is approved for a K-6 license in Elementary Education and a K-12 license in Mild/Moderate Disabilities. There are three phases for education majors: Phase I: Core Curriculum; Phase II: Teacher Education Program; and Phase III: Student Teaching.

\subsection{Phase I: Core Curriculum}

The required core curriculum is based on freshmen and sophomore level coursework in English, social and behavioral science, mathematics, science, humanities and fine arts. The core curriculum ranges from 41 to 45 hours depending on degree program.

\subsection{Phase II: Teacher Education Program}

Requirements for admission to Phase II (Teacher Education Program), in compliance with Mississippi Senate Bill 2188, include: 
1) Completion of core curriculum;

2) A minimum core grade point average of 2.75 ;

3) Passing scores on Praxis Core Academic Skills for Educators (CORE)*.

*Exemption: Students who provide proof of an SAT score of at least 990 (verbal and quantitative) or an ACT score of at least a 21 overall composite with no scores lower than 18 in the other 4 subject areas are exempt from taking the Praxis CORE. We do not superscore for the ACT and/or SAT.

Prior to admission to Phase II, students may enroll in two introductory professional education courses-EDCI 352 Education, Society, and the K-12 Learner and EDSP 308 Introduction to Special Education. Elementary Education majors may also take EDRD 355 Early Literacy Instruction. A minimum grade of "C" is required in all professional education courses.

\subsection{Phase III: Student Teaching}

Prior to advancing to Phase III, a student must successfully complete the core curriculum, general education courses and all professional education courses with a minimum grade of " $C$ ".

Mississippi Universities are governed by the Board of Trustees which is the constitutional governing body for the State Institutions of Higher Learning (IHL). The Board oversees degree-credit courses, research and public service activities and programs at the eight public universities. This board directed all Universities to review credit hour requirements for all undergraduate degrees to reduce the expectation of degree program requirements to no more than 124 hours. A set of core courses was agreed upon across all public postsecondary institutions. The core must be fully transferable at all public institutions. Table 1 compares the previous degree requirements to the new merged program requirements.

Table 1. Program requirements.

\begin{tabular}{|c|c|c|c|}
\hline Previous program & Hrs. & Merged program & \\
\hline Core curriculum & 45 & Core curriculum & 41 \\
\hline English composition & 6 & English composition & 6 \\
\hline Social/behavior sciences & 9 & $\begin{array}{l}\text { Social/behavior sciences removed PSY } 201 \text { (3) } \\
\text { added GEO (3); Pol Sci or Soc (3) }\end{array}$ & 12 \\
\hline Mathematics/science & 15 & Mathematics/science-removed an elective in math/science & $12-15$ \\
\hline Humanities/fine arts & 15 & Humanities/fine arts-removed fine arts and humanities electives & 9 \\
\hline General education & 30 & $\begin{array}{c}\text { General education } \\
\text { Math, art, music, and writing }\end{array}$ & 15 \\
\hline Professional education & 41 & $\begin{array}{l}\text { Professional education } \\
\text { Method and reading courses with special education (12 hours) courses }\end{array}$ & 57 \\
\hline Concentration area 1 & 18 & Concentration area 1 & 18 \\
\hline Concentration area 2 & 18 & Concentration area 2 & 18 \\
\hline Total program requirement & 129 & Total program requirement & 124 \\
\hline
\end{tabular}




\section{Field Placements for the Merged Program}

During the professional education common-core coursework, teacher education candidates are required to observe and teach in selected classrooms, learning about effective teaching, developing professional dispositions, and working directly with practitioners and school students at varying grade and developmental levels. Our field experience enables candidates to acquire instructional and curricular competence in diverse general education classrooms and schools and provides multiple opportunities to develop collaboration skills with general and special education colleagues, related service personnel, and families.

The field-based experiences are planned so that the knowledge, theories, and practices taught in the University classroom are applied in meaningful ways at selected points in the program. During the professional education common-core coursework, teacher education candidates are required to observe and teach in selected classrooms, interview teachers and reflect on lessons taught. Candidates develop and refine understanding of teaching and learning as a facilitative process and begin to apply principles of developmental/constructivist theory through instructional practice. Learning about effective teaching, developing professional dispositions and participating in field-based experiences provide candidates the opportunity to work directly with practitioners and school students at varying grade and developmental levels. Interaction with teaching candidates in all three program areas within the common core is purposefully planned to allow for discussion of similarities and differences within field experiences. Field experiences begin with Introductory Field Experiences during the candidate's sophomore or junior year. The candidate then moves to the year-long internship, which includes the senior practicum and student teaching semesters. For their field experiences, teacher education candidates are assigned to schools/districts and grade levels that are diverse in demographics and student population.

All teacher education candidates must demonstrate appropriate skills and behaviors when completing placements in the field. Teacher education candidates are expected to exhibit the dispositions defined by the Council for the Accreditation of Educator Preparation (CAEP) as the values, commitments, and professional ethics that influence behaviors toward students, families, colleagues and communities and affect student learning, motivation and development as well as the educator's own professional growth. Dispositions are guided by beliefs and attitudes related to values such as caring, fairness, honesty, responsibility and social justice.

\section{Student Advising and Field Experience Office}

The School of Education's Student Advising and Field Experience (SAFE) Office serves as the liaison between the various teacher education programs for implementing field experiences. The office implements all approved standards and policies governing field experiences, Senior Practicum, and Student Teaching. It works with candidates, supervisors, and site administrators in the placement of 
candidates for all field experience placements.

All candidates complete their field experiences in a Network of Professional School (NPS) sites. These NPS sites are specifically structured schools in which the P-12 school and higher education faculty collaborate to provide introductory, practicum, and student teaching field experiences. These sites also support the professional development of school and higher education faculty, enable inquiry directed at the improvement of practice, and enhance student achievement. NPS sites require the institutional commitment of colleges and universities, school districts, and teacher organizations.

The SAFE office uses NPS sites for field-based and clinical experiences for the elementary, secondary, and special education programs. School districts have been identified as sites on the basis of the following criteria:

- Schools that have developed and implemented programs recognized professionally as significant;

- Schools committed to focus on programs for a diverse population of students and exhibit such populations;

- Schools with classroom teachers who are selected to become clinical instructors by their district and the University teacher education faculty because they demonstrate outstanding professional leadership, excellence in teaching, and model facilitative learning consistent with the teacher education knowledge base, "Educators as Reflective Professionals";

- Schools with classroom teachers who exhibit a desire for continuing growth and professional development of all their teachers;

- Schools committed to assuming responsibility for continuing growth and professional development;

- Schools committed to nurturing future professionals as part of their mission;

- Schools with clinical instructors who have received training by University supervisors and the Student Advising and Field Experience office (SAFE);

- Schools committed to exploring and generating new knowledge about teaching and learning;

- Schools in locations with a history of community support and potential for extending that support;

- Schools located in North and North Central Mississippi where clustering of University students is possible.

The SAFE office is instrumental in selecting the clinical instructors from our NPS sites who work with the teacher candidates. The SAFE office selects clinical instructors committed to professional development and improvement of the NPS partnership. Clinical instructors must also express interest in professional growth, an ability to exhibit facilitative behaviors which focus on meaningful student learning, and have three or more years of classroom teaching experience. Recommendation of NPS administrators and University faculty are also considered when selecting clinical instructors.

The School of Education's in-house assessment system plays an important role in the collection of assessment data from multiple sources including candi- 
dates, recent graduates, faculty, clinical instructors, principals, and external reviewers. These data are systematically compiled, summarized, and analyzed annually to assist in making improvements that have a positive impact on candidate performance, program quality, and unit operations. The process provides an empirical basis for informing, evaluating, and continuously improving the unit and its educator preparation programs.

One of the vital assessments collected in the assessment system is the Teacher Intern Assessment Instrument (TIAI). The TIAI is used to assess the performance of teacher candidates field work. The TIAI is based on ten standards developed by the Interstate New Teacher Assessment and Support Consortium (INTASC). The clinical instructor and university supervisor share responsibility for assessment of the teacher candidate. The TIAI indicators are incorporated into five domains: 1) Planning and Preparation, 2) Assessment, 3) Instruction, 4) Learning Environment, and 5) Professional Responsibilities. The TIAI consists of 25 indicators with individualized criteria for each indicator. Each set of criteria includes the following four levels: Target ( 3 points), Acceptable ( 2 points), Emerging (1 point), and Unacceptable (0 points).

Candidates are assessed using the TIAI at four points throughout the undergraduate program. The first TIAI assessment of candidate performance happens during the junior year when candidates have their first experience planning and teaching a unit of study during a 45 -hour field placement. The subsequent TIAI evaluations occur during the year-long senior placement which culminates in the student teaching experience.

\section{Crucial Components for Implementing Change}

Redesigning the program required a fundamental shift in the role of faculty and their delivery of instruction. For most, this shift represented minor instructional changes or opportunities to expand their teaching repertoire. For others, the changes presented dramatic shifts in philosophical considerations as well as shifts in instruction and delivery systems-a break from their current practice. Thus, the magnitude of the initiative for some faculty represented a first-order change-an extension of current practices and beliefs-and for others who viewed the initiative as a critical departure from the norm, a second-order change. Organizational theorists who specialize in second-order change or "deep change" (Waters, Marzano, \& McNulty, 2004a, 2004b), refer to this as "below the surface" (Gersick, 1991) structures that include the attitudes, values, beliefs, and expectations that drive the behavior of individuals (Schein, 1990). Therefore, "the phenomenon of first- versus second-order change is an internal event ... defined by the way people react to a proposed innovation" (Marzano, Waters, \& McNulty, 2005).

To address the varying degrees of faculty resistance and levels of expertise, faculty met in collaborative teams to discuss, plan, and develop the new curriculum. Together, faculty experiencing both first and second-order change examined their "basic philosophical beliefs about teaching, learning, the nature of 
human beings, and the kinds of environments that maximize growth for teachers and students alike" (Michaels, 1988). Over a period of months, these conversations provided a safe and productive opportunity to align their beliefs and pedagogy to solidify a cohesive integrated program. Additionally, this process provided an opportunity for faculty ownership, a deeper understanding of the curriculum and its purposes, and a broader acceptance of the new program. Thus, faculty became the key factors in the development and the successful implementation of this program reform effort.

\section{Expansion and Conclusion}

Today's pre-service teacher preparation programs must prepare professionals who advocate for diverse learners through well-developed content knowledge, effective pedagogical skills in both special and general education, and appropriate intervention skills developed around evidence-based practices. The goal of our program reform effort was to design an integrated elementary special education preservice licensure program that sought to modify the role of faculty and gave students the more authentic preparation experience through action labs and field experiences. Our faculty engaged in a successful collaborative process by incorporating Baker's (1998) three factors associated with second-order changes: 1) a fundamental change in ideas about and actions toward student achievement; 2) instructional enhancement focused on refining pedagogy, and; 3) collaborative support that replaces a culture of isolation. The success of the reform effort was directly related to the collaborative nature of the process and the leadership. Based on our experience, this collaboration is essential if faculty is to faithfully implement the requisite changes.

Elementary and special education candidates have gained valuable learning experiences through the integrated curriculum and program redesign. In annual School of Education data, our graduating seniors report that their preparation program: 1) enables their participation in the collaborative design and implementation of a multi-tiered system for both academic and behavioral areas; 2) prepares them to become collaborative teaching professionals attributing this to their extensive pre-service experience across diverse general education settings; 3) provides them with the skills to provide and model supports for students who are at-risk for exhibiting challenging behavior and not at grade level for academics; and 4) provides needed experiences so they are comfortable entering schools and showing support for efforts toward more inclusive services for all students. Furthermore, graduates of the integrated program, who are practicing elementary or special education teachers, report their ability to a) develop and support the instruction of grade level standards-based goals and objectives; b) demonstrate parity in their knowledge and implementation of instruction with their general education teacher peers and differentiating for diverse needs in general education classrooms; and c) move within schools from special education to general education roles and vice versa during careers. Our graduates note that they feel more prepared to deal with the diverse needs of students than their 
counterparts who have completed programs at other institutions, which don't integrate the special education curriculum. Our integrated elementary special education program presents a framework that provides our students with the knowledge and skills needed to meet the demands of accountability with a diverse student body.

After a period of more than five years of implementation, we view this reform effort as successful in creating two fundamental improvements in our teacher education program: an effective, integrated elementary special education program and a culture of trust and collaboration among the teacher education faculty.

\section{References}

Baker, D. B. (1998). The Implementation of Alternative Assessment Procedures and Washington State Reform. Seattle, WA: Washington School Research Center, Seattle Pacific University.

Blanton, L. P., \& Pugach, M. C. (2007). Collaborative Programs in General and Special Teacher Education: An Action Guide for Higher Education and State Policymakers. Center for Improving Teacher Quality. Washington DC: Council of Chief State School Officers.

http://programs.ccsso.org/content/pdfs/CPGSTE\%20Action\%20Guide\%20PDF\%20Fin al.pdf

Brownell, M. T., Sindelar, P. T., Kiely, M. T., \& Danielson, L. C. (2010). Special Education Teacher Quality and Preparation: Exposing Foundations, Constructing a New Model. Exceptional Children, 76, 357-377.

Every Student Succeeds Act (ESSA) of 2016, PL 114-95, 20 U.S.C. $\$ \$ 6301$ et seq.

Gersick, C. J. (1991). Revolutionary Change Theories: A Multilevel Exploration of the Punctuated Equilibrium Paradigm. Academy of Management Review, 16, 10-36. https://doi.org/10.5465/AMR.1991.4278988

Individuals with Disabilities Education Improvement Act (IDEIA) of 2004, PL108-446, 20 U.S.C. $\$ \$ 1400$ et seq.

Kamens, M. W. (2007). Learning about Co-Teaching: A Collaborative Student Teaching Experience for Preservice Teachers. Teacher Education and Special Education. The Journal of the Teacher Education Division of the Council for Exceptional Children, 30, 155-166.

Marzano, R. J., Waters, T., \& McNulty, B. A. (2005). School Leadership That Works: From Research to Results. Alexandria, VA: Association for Supervision and Curriculum Development.

United States Congress (2001). No Child Left Behind Act of 2001, 20 U.S.C. 70 Section 6301 et seq. Washington DC: United States Congress.

Sailor, W. (2002). President's Commission on Excellence in Special Education. Washington DC: Department of Special Education.

Schein, E. H. (1990). Organizational Culture (p. 109). Washington DC: American Psychological Association.

Shippen, M. E., Crites, S. A., Houchins, D. E., Ramsey, M. L., \& Simon, M. (2005). Preservice Teachers' Perceptions of Including Students with Disabilities. Teacher Education and Special Education: The Journal of the Teacher Education Division of the Council for Exceptional Children, 28, 92-99. https://doi.org/10.1177/088840640502800202

Van Laarhoven, T. R., Munk, D. D., Lynch, K., Bosma, J., \& Rouse, J. (2007). A Model for 
Preparing Special and General Education Preservice Teachers for Inclusive Education. Journal of Teacher Education, 58, 440-455.

https://doi.org/10.1177/0022487107306803

Waters, J. T., Marzano, R. J., \& McNulty, B. (2004a). Leadership that Sparks Learning. Educational Leadership, 61, 48.

Waters, J. T., Marzano, R. J., \& McNulty, B. (2004b). McREL's Balanced Leadership Framework: Developing the Science of Educational Leadership. ERS Spectrum, 22, 410.

Submit or recommend next manuscript to SCIRP and we will provide best service for you:

Accepting pre-submission inquiries through Email, Facebook, LinkedIn, Twitter, etc. A wide selection of journals (inclusive of 9 subjects, more than 200 journals) Providing 24-hour high-quality service User-friendly online submission system Fair and swift peer-review system Efficient typesetting and proofreading procedure Display of the result of downloads and visits, as well as the number of cited articles Maximum dissemination of your research work

Submit your manuscript at: http://papersubmission.scirp.org/

Or contact ce@scirp.org 